\title{
A PROTEÇÃO DOS DIREITOS FUNDAMENTAIS PELA AÇÃO FOTOJORNALÍSTICA: O ESTUDO DE CASO JAMES NATCHWEY ${ }^{1}$
}

THE PROTECTION OF FUNDAMENTAL RIGHTS BY PHOTOJORNALISTIC ACTION: THE JAMES NATCHWEY CASE STUDY

Ingrid Helena TAVARES ${ }^{2}$

Manoel Ilson Codeiro ROCHA ${ }^{3}$

ISSUE DOI: $10.21207 / 2675-0104.2018 .732$

\section{RESUMO}

A indagação do presente artigo científico fundamenta-se na proteção de direitos fundamentais do Direito Internacional Humanitário pela ação artística foto jornalística: o estudo de caso James Natchwey.O assunto central em que a temática se insere encontra-se no rol das regras e princípios fundamentais do Direito Internacional Humanitário. No momento em que se reconhece no acervo fotográfico de Natchwey o grito de socorro da humanidade percebe-se que a consequiência dos conflitos armados envolve desde o estado de miserabilidade dos povo até a negligência no âmbito da saúde. Tratados internacionais surgiram com o intuito de coibir as práticas penosas e desumanas no contexto da Guerra, porém, para que surgissem tais tratados, a sociedade civil estabeleceu formas denunciativas pleiteando melhores condições para os civis e ex combatentes. Natchwey usou suas fotografias para

${ }^{1} \mathrm{O}$ presente artigo sintetiza a monografia de conclusão da pesquisa, realizada para o Programa Interno de Bolsas de Iniciação Científica (PIBIC 2017-2018) da Faculdade de Direito de Franca (FDF), Franca/SP.

${ }^{2}$ Discente da Faculdade de Direito de Franca (FDF), Franca/SP. Bolsista do Programa Interno de bolsas de Iniciação Cientítica (PIBIC 2017-2018).

${ }^{3}$ Graduado em Direito pela Universidade Estadual Paulista-UNESP (1996). Mestre em Direito Público pela Universidade Estadual Paulista - UNESP (2000). Doutor em Direito Administrativo pela Universidade de Lisboa - UL (2015). Atualmente é professor de Direito Internacional na Faculdade de Direito de Franca. 
denunciar o que presenciava nos campos de batalha. Através de seu olhar sensível contou sobre a cultura da tortura, do genocídio e da violência. A cada fotografia exposta demonstrar-se-á a referida violação dos Direitos Fundamentais, bem como a tipificação concernente para coibir tal ato.

Palavras-chave: Direitos fundamentais. Fotografias. James Natchwey.

\section{ABSTRACT}

The inquiry of this scientific article is based on the protection of the fundamental rights of International Humanitarian Law by the artistic action journalistic photo: the James Natchwey case study. The central theme in which the theme is inserted lies in the list of the fundamental rules and principles of international humanitarian law. At a time when Natchwey's photographic collection recognizes humanity's cry for help, one notices that the consequences of armed conflict range from the state of people's misery to health neglect. International treaties arose in order to curb the painful and inhuman practices in the context of the war, but for civilian and ex-combatants civil society established denunciatory forms for civilian and ex-combatants. Natchwey used his photographs to denounce what he saw on the battlefields. Through his sensitive eye he told about the culture of torture, genocide and violence. Each photograph exposed will demonstrate the aforementioned violation of the Fundamental Rights, as well as the pertinent typification to restrain such act.

Keywords: Fundamental rights. Photos. James Natchwey.

\section{INTRODUÇÃO}

Também conhecido como Direito de Guerra, o Direito Internacional humanitário tem origem nos acordos promovidos entre os Estados. O referido surgiu da ânsia em manter um equilíbrio entre as incumbências militares do Estado e os interesses humanitários. Um dos principais desafios contemporâneos é identificar de que forma a sociedade civil pode fornecer uma ajuda efetiva nos procedimentos investigatórios e denunciativos em relação às violações dos Direitos Fundamentais. Pretende-se ressaltar que atualmente entre o sensacionalismo e a languidez, há quem concorde que existe uma superexposição das vítimas dos conflitos armados pela mídia.

Em contrapartida há também quem acredite que o trabalho de fotógrafos de guerra são intervenções positivas visando sensibilizar a sociedade civil acerca de um mal que sempre existiu, possibilitando a busca de soluções com o fim de amenizar os efeitos da Guerra. Cria-se, então, uma atmosfera onde uma sociedade bem informada passa a buscar cada vez mais transformações. A fotografia como veículo informacional surgiu a partir do momento que a sociedade reconheceu que o conteúdo midiático representativo era tão importante quanto ao componente escrita.

Metaforicamente falando, as violações dos direitos fundamentais em períodos de guerra podem ser representadas como um corte profundo. A ação fotojornalística, por sua vez, não funciona como um curativo que estancaria a ferida, nem como analgésico que serviria somente para 
amenizar durante algum tempo as conseqüências do corte. Porém, o jornalismo, pode sim, assemelhar-se a um simples ato que faz parte do rol de primeiros socorros: momento em que alguém mais próximo à vitima contata pessoas indicadas para agir para sarar o ferimento, no caso, os médicos.

Os civis, apesar de limitadamente, podem contribuir nos cenários marcados pelos conflitos, sendo assim se há uma maior conscientização da massa a respeito da miséria, enfermidades e afins que acompanham os conflitos armados será mais fácil atribuir ao Estado à responsabilidade de reparar os danos causados e por fim, cobrar uma maior efetividade da parte dos governantes.O interesse pela realização da pesquisa deu-se a partir do momento em que se reconhece que o mundo, segundo dados da Organização das Nações unidas, enfrenta uma das maiores crises humanitárias desde a segunda guerra mundial.

Portanto, a importância do tema sob uma perspectiva geral concentra-se na efetivação dos direitos fundamentais assegurados em tratados e convenções internacionais, porém abordando um viés sócioartistico, partindo do fato de que a arte, como forma de expressão, é capaz de causar impressões visuais perturbadoras, provocando uma forte repercussão midiática

\section{UM PANORAMA DOS CONFLITOS ARMADOS}

Incumbe aos historiadores e sociólogos estabelecer motivos que levaram os povos a guerrearem. Primordialmente, há a necessidade de traçar um conceito etimológico para o termo guerra. Segundo Antenor Nascente (1995) a palavra guerra possui origem germânica da palavrawerra, vocábulo até então, incorporado ao Frâncico, língua dos Francos, antigo povo germânico.

Ao analisar minuciosamente a questão dos conflitos armados, em sua obra Da Guerra, conceitualmente Clausewitz afirma que "A guerra é uma simples continuação da política por outros meios.” (CLAUSEWITZ, 1997: 27). De modo inteligível, o referido teórico apresenta a essência da guerra, afirmando "Não comecemos por uma definição da guerra, difícil e pedante, limitemo-nos a sua essência, ao duelo. A guerra nada mais é que um duelo em uma escala mais vasta." (CLAUSEWITZ, 1996: 7).

À medida que o homem passou a viver em sociedade, surgiram os primeiros conflitos entre eles. Há relatos de que no sítio arqueológico 
de Nataruk no Quênia foram encontrados esqueletos fossilizados de um clã de caçadores, vítimas de um massacre há 10.000 anos. Membros da equipe de arqueólogos, liderados por Marta MirazonLahr da Universidade de Cambridge, constataram que os esqueletos encontrados possuem traumas nas costelas, crânios, joelhos e até mesmo lesões que ao que tudo indica foram feitos por flechas e pedras.

Já a Idade Média pode ser considerada como o período da revolução das armas, que influenciou os armamentos militares modernos. As principais guerras são as Cruzadas, a Guerra civil Inglesa, a Guerra dos Cem Anos, entre outras. Entre o século XVI e o Século XIX, destaca-se Guerra dos Trinta Anos, a Independência dos Estados Unidos, a Guerra do Ópio, Guerra da Criméia, Guerra do Paraguai e no Brasil, cita-se a Guerra Canudos, representando a batalha como nos dizeres de Euclides da Cunha:

\begin{abstract}
Canudos não se rendeu. Exemplo único em toda a História, resistiu até ao esgotamento completo. Expugnado palmo a palmo, na precisão integral do termo, caiu no dia 5, ao entardecer, quando caíram os seus últimos defensores, que todos morreram. Eram quatro apenas: um velho, dois homens feitos e uma criança, na frente dos quais rugiam ruidosamente cinco mil soldados" (CUNHA, 2003, p. 756).
\end{abstract}

Finalmente, após analisar aspectos básicos sobre os conflitos armados, é importante argumentar no tocante asegurança internacionale a segurança humana no cenário global. De acordo Buzan e Hansen (2009), a preocupação com a segurança internacional emergiu no período pós Segunda Guerra Mundial. Constituindo-se um método de discussão sobre as desavenças contra os Estados, averiguando desta forma, diversas táticas para protegê-los. Contudo, até meados do fim do século XX, o Estado era o eixo destes estudos, consequentemente a única figura a ser protegida. Deste modo, segundo Blanco (2014):

\footnotetext{
[...] os estudos sobre segurança seguiram uma linha de pesquisa com um caráter mais militarista, voltado à estratégia. Sob essa ótica, a principal ameaça à segurança internacional consistia essencialmente em elementos que afetassem a segurança estatal, como, por exemplo, a proliferação nuclear ou um conflito armado aberto entre dois Estados beligerantes (BLANCO, 2014).
}

A guerra não se restringe tão somente aos enfrentamentos entre Estados, mas abrange também as lutas presentes dentro dos Estados, implicando em um evento extensivo nos parâmetros transnacional e transfronteiriço. Um dos institutos mais importantes estudados no ramo do 
Direito é o Direito Internacional dos conflitos armados. Para Christophe Swinarski, 1996, o DICA pode ser conceituado como o aglomerado de regras internacionais designada para ser utilizada nos conflitos armados, limitando por fatores humanitários, o direito de escolha das partes dos métodos e os utilizados na guerra.

Em conformidade com a evolução social a celebração de tratados de paz e acordos internacionais foram fortificando-se. Sendo assim, no momento em que surgiu a necessidade de regularizar medidas protetivas das vítimas de conflitos armados, criou-se a primeira codificação internacional normativa com a finalidade de proteção dos feridos e doentes nos campos de batalha (Convenção de Genebra, em 1864).

\section{3}

\section{O OLHAR HUMANITÁRIO DE JAMES NATCHWEY E O INFLUXO SÓCIO-JURÍDICO DA FOTOGRAFIA}

A datar do período pré-histórico, os homens primitivos representavam a existência e seus costumes por meio de pinturas. Cada representação, desenho e gravura constituíram-se como berço para a fotografia. A fotografia é, de acordo com Bellone (1997 apud BORGES, 2008), a arte de fixar a luz de objetos mediante a ação de certas substâncias. Todavia, uma foto é mais do que o descrito, é a perpetuação do presente, trata-se de um registro visual vetor de informações e emoções.

A fotografia tornou-se potencial e tornou-se preferida em detrimento aos textos, que se tornaram tão somente complemento da imagem. Sendo assim, a função mais importante da fotografia desde a sua invenção é informar. Sousa (2002) diz que as fotografias jornalísticas são as que são usadas para transmitir uma informação útil à sociedade. $\mathrm{O}$ autor afirma que:

O Fotojornalismo é, na realidade, uma atividade sem fronteiras claramente delimitadas. $\mathrm{O}$ termo pode abranger quer as fotografias de notícias, quer as fotografias dos grandes projetos documentais, passando pelas ilustrações fotográficas e pelos features (as fotografias intemporais de situações peculiares com que o fotógrafo depara). De qualquer modo, como nos restantes tipos de jornalismo, a finalidade primeira do Fotojornalismo, entendido de forma lata, é informar. (SOUSA, 2002, p. 7)

O fotógrafo documentarista possui a liberdade de conduzir a cena, sendo assim, "A imagem de qualquer objeto ou situação 
documentada pode ser dramatizada ou estetizada, de acordo com a ênfase pretendida pelo fotógrafo em função da finalidade ou aplicação a que se destina." (KOSSOY, 2002, p.52).

Ao documentar a realidade por meio da arte fotográfica surge o compromisso com um determinado tempo e um determinado espaço. Foi isso que o fotógrafo de Guerra James Natchwey conquistou em seu trabalho. Convalida-se, portanto, que a presente monografia visa analisar o influxo sócio jurídico da fotografia por meio do estudo de caso de James Natchwey.

James Natchwey, norte-americano, nascido em Syracusee criado em Massachusetts, formou-se na Dartmouth College, onde estudou História da Arte e Ciências Políticas. É um importante fotógrafo comparado com Robert Capa por seus registros de guerra. Natchweytrabalha para a conceituada Revista Time e ao percorrer lugares conflituosos como Israel, Indonésia, Tailândia, Índia, Guatemala e Coréia do Sul registrou imagens perturbantes. James Natchwey (2007) revela:

Eu era um estudante nos anos 60, uma época de desordem social e indagação, e num nível pessoal, do despertar de um senso de idealismo. A Guerra do Vietnã se intensificava, o Movimento dos Direitos Civis estava em marcha, e fotografias me influenciavam poderosamente. Nossos líderes políticos e militares nos diziam uma coisa, e os fotógrafos nos contavam outra. Eu acreditava nos fotógrafos, assim como milhares de outros americanos. Suas imagens alimentavam a resistência contra a guerra e o racismo. Eles não somente registraram a história; mas também ajudaram a mudar o seu curso. Suas fotos se tornaram parte de nossa conscientização coletiva. e, conforme a conscientização evoluiu num senso de consciência comum, mudanças se tornaram não apenas possíveis, mas inevitáveis (...) Os problemas da sociedade não serão resolvidos até que sejam identificados. Num plano superior, a imprensa é uma indústria de serviços, e o serviço que ela oferece é a conscientização. Cada reportagem não precisa vender algo. Existe também um tempo para dar. Essa era a tradição que eu queria seguir. Percebendo que a guerra criava riscos gigantescos para todos os envolvidos e que o jornalismo visual poderia se tornar um agente na resolução de conflitos, eu quis me tornar um fotógrafo, para assim ser um fotógrafo de guerra. Mas eu era movido por uma intuição inata de que a foto que revelasse a verdadeira face da guerra seria quase por definição uma foto contra a guerra.

A grande questão atual é se as imagens de Guerra ao serem publicadas realmente influem para a formação de um pensamento crítico responsável por gerar uma consciência sobre a dor do outro. Natchwey, em seu trabalho retrata aspectos dos Direitos Fundamentais e principalmente, 
da empatia em meio a tanta selvageria. A repercussão da fotografia na construção do direito não ficou suficientemente demonstrada, porém, para James (2007),

Fotógrafos vão às fronteiras extremas da experiência humana para mostrar aos outros o que está acontecendo. Algumas vezes eles põem suas vidas em linha, porque eles acreditam que a sua opinião e influência fazem a diferença. Eles focam suas fotos em nossos melhores instintos, generosidade, um senso de certo e errado, a habilidade e a vontade de se identificar com os outros, a recusa de aceitar o inaceitável.

Como exemplo de como o fotojornalismo é supra importante em seu papel denunciativo, observa-se a imagem abaixo:

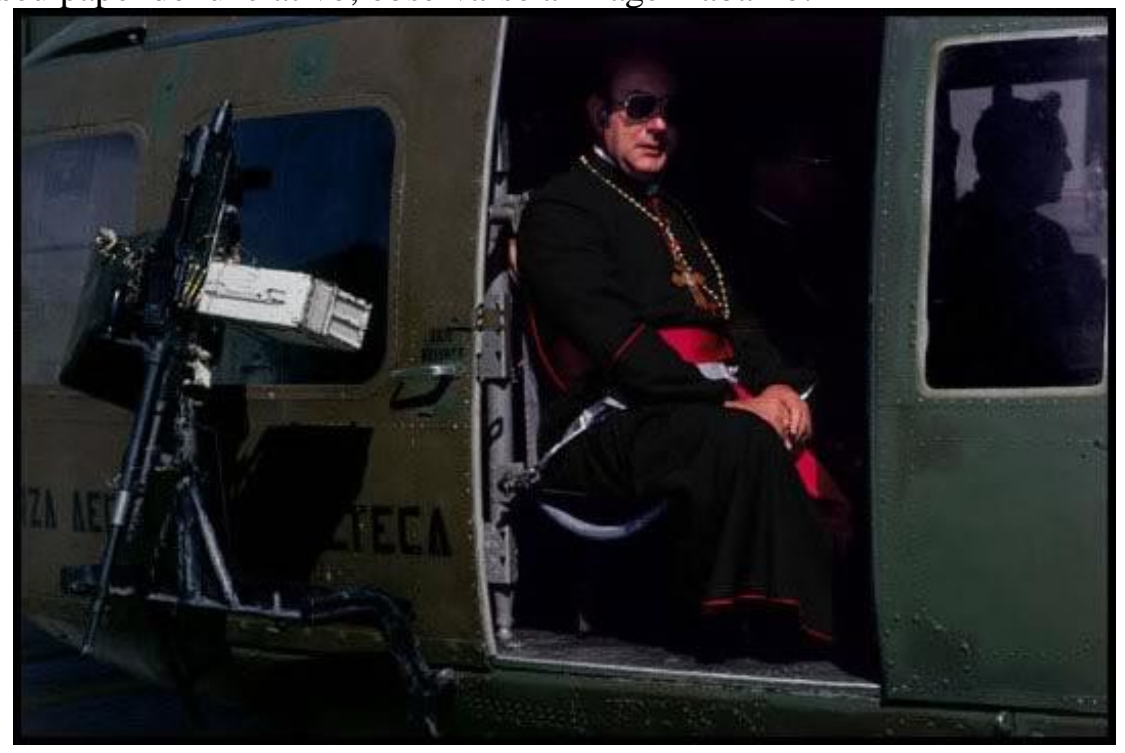

Figura 3 Guatemala, 1983- O clero viajou em helicópteros militares para a massa de Papa João Paulo II na zona de guerra.

$\mathrm{Na}$ Guatemala, o governo central -- controlado por uma oligarquia de origem européia promovia uma guerra de aniquilação contra uma rebelião indígena, e eu vi uma imagem que refletia a história da América Latina: a conquista através da cruz e da espada. (JAMES NATCHWEY, 2007)

James Natchwey traz em seu discurso a respeito sobre a imagem retrata o termo "genocídio". Tal nomenclatura foi utilizada pela primeira 
vez no ano 1944 para se referir às vítimas do nazismo. Averigua-se que a Convenção para a Prevenção e a Repressão do Crime de Genocídio de 1948, em seu artigo $2^{\circ}$, traz a seguinte definição:

\footnotetext{
Na presente Convenção, entende-se por genocídio os atos abaixo indicados, cometidos com a intenção de destruir, no todo ou em parte, um grupo nacional, étnico, racial ou religioso, como tal: a) Matar membros do grupo; b) Causar lesão grave à integridade física ou mental de membros do grupo; c) Submeter intencionalmente o grupo a condições de existência capazes de ocasionar-lhe a destruição física total ou parcial; d) Adotar medidas destinadas a impedir os nascimentos no seio do grupo;
}

Vale lembrar que a Assembléia Geral da Organização das Nações Unidas, em sua Resolução 96 (I), de 11 de dezembro de 1946, declarou que o genocídio é um crime contra o Direito Internacional, contrário ao espírito e aos fins das Nações Unidas e que o mundo civilizado condena. Destarte, o extermínio dos povos é repudiado pela comunidade internacional e como conseqüência os Estados adotam medidas de prevenção e repressão a todo e qualquer ato que remetem a esse fim.

Portanto, ao falar da guerra, percebe-se que tal termo não se restringe somente ao plano da significação. Embora grande parte das pessoas saiba explicar o que de fato é um conflito armado - mesmo sem nunca terem vivenciado esse fenômeno -, escassas são as pessoas que se dispuseram a ponderar sobre tal evento.

À medida que o homem passou a viver em sociedade, surgiram os primeiros conflitos entre eles. Após definir conceitos e traçar similaridades entre o rol de Direitos Humanos, o Direito Internacional humanitário e os Direitos fundamentais, pode-se concluir que um é a complementaridade do outro.

Não há como defender um Estado que garante os Direitos Fundamentais, porém vive emerso em uma Guerra Total e também não há como falar de um Estado promotor de Direitos Humanos que não fornece dignidade para as pessoas que ali habitam.

Desponta na atualidade, um novo objeto de destaque e discussão na comunidade internacional. Inúmeros são os profissionais que propõe a ponderação entre o Direito e Arte. Os motivos deste fato são complexos e abrangem desde o ímpeto do mercado internacional de artes plásticas até mesmo exigüidade da linguagem jurídica, confirmando deste modo o advento da transjurisdicidade para a melhor compreensão dos elementos normativos. 
Trata-se basicamente de associação indispensável para uma idealização mais humana e crítica dos juristas e profissionais da lei.Sendo assim, a grande questão atual é se as imagens de Guerra ao serem publicadas realmente influem para a formação de um pensamento crítico responsável por gerar uma consciência sobre a dor do outro e consequentemente acabam por influir na esfera das decisões políticas

\section{CONCLUSÃO}

Conclui-se, portanto, que em meio a tanta selvageria inerente a guerra, o DIH, os Direitos Humanos e os Direitos fundamentais apesar de possuírem diferenças pontuais, dispõe da mesma finalidade: proteger e garantir uma vida digna às pessoas que vivem em meio a Conflitos armados. Como resultado tem-se que a questão artística surge para desmistificar ideia e que o Direito é uma ciência tão somente normativa, vez que ao analisar o acervo fotográfico de James Natchwey confirma-se que as imagens retratadas são formas de denúncia das violações dos Direitos Fundamentais. A partir da denúncia fotojornalística a sociedade torna-se empática. Deste, o próprio fotógrafo confirma que usa sua fotografia para incitar uma abordagem critico-social a respeito do fenômeno da guerra, gerando assim, debates políticos e uma maior atenção ao envolvidos nas áreas de conflito. Porém, insta-se que a repercussão da fotografia na construção do direito não ficou suficientemente demonstrada.

\section{REFERÊNCIAS BIBLIOGRÁFICAS}

ARENDT, Hannah. Origens do totalitarismo. Tradução de Roberto Raposo. São Paulo: Companhia das Letras, 1990.

ARNAUD, Raphael Carneiro. Uma simbiose necessária para uma construção mais humanista e crítica dos juristas.Site:https://jus.com.br/artigos/47369/direito-e-arte - Acesso em: 06 de fev de 2018.

ARON, R. Pensar a guerra, Clausewitz: a era européia. Brasília: UnB, 1986a.

ARON, R. Pensar a guerra, Clausewitz: a era planetária. Brasília: UnB, 1986b.

BOBBIO, Norberto. O problema da guerra e as vias da paz. São Paulo: Editora UNESP, 2003;

BONAVIDES, Paulo. Curso de direito constitucional. 3. ed. São Paulo: Malheiros, 2009. 
BORGES, Maria Eliza Linhares. História \& Fotografia. $2^{\mathrm{a}}$ ed., $1^{\mathrm{a}}$ reimp. Belo Horizonte: Autêntica, 2008. $132 \mathrm{p}$.

BRASIL. (Constituição 1988). Constituição da República Federativa do Brasil.

BUITONI, Dulcilia Schroeder. Fotografiae jornalismo: a informação pela imagem.Magaly Prado (organizadora da coleção). São Paulo: Saraiva, 2011. 195 p. (Introdução ao Jornalismo; v. 6).

BULOS, UadiLammêgo. Direito constitucional ao alcance de todos. São Paulo: Saraiva, 2008. Disponível em: .Acessoem: 06 fev. 2018.

BUZAN, Barry. (1991). People, States and Fear: An Agenda for International Security Studies in the PostCold War Era. Boulder (Colorado), LynneRienner.

CANOTILHO, José Joaquim Gomes.Direito constitucional e teoria da constituição. 3. ed. Coimbra: Almedina, 1998.

Direito constitucional. 7. ed. Coimbra: Almedina, 2002.

CHAVES, Marianna. "Modos de extinção do contrato de empreitada: um panorama lusobrasileiro", In: Revista Fórum de Direito Civil - RFDC, Belo Horizonte, ano 1, n. 1, pp. 29-54, set./dez. 2012.

CLAUSEWITZ, C. On war. Princeton: Princeton University Press, 1984

COMITÊ INTERNACIONAL DA CRUZ VERMELHA. Os tratados do DIH e o DIH consuetudinário. Disponível em: . Acesso em: 06 fev. 2018

CUNHA, Paulo Ferreira da. "Do direito fundamental à cultura: notas contemporâneas politicamente incorretas", In: Hermenêutica, Justiça Constitucional e Direitos Fundamentais Fundamentais/ Jorge Miranda et al. (Coords). Curitiba: Juruá, pp. 291-302, 2016, p. 291.

DEYRA, Michel. Direito Internacional Humanitário. Lisboa: Gabinete de Documentação e Direito Comparado, 2001.

FRANCA, Marcílio Toscano. Relação entre Direito e arte é discutida por juristas em Berlim. Site: https://www.conjur.com.br/2016-dez-12/direito-civil-atual-relacao-entre-direito-arte-discutidajuristas-berlim - Acesso em: 06 de fev de 2018.

HIRONAKA, Giselda Maria Fernandes Novaes. "O conceito de família e sua organização jurídica", em Tratado de Direito das Famílias/Rodrigo da Cunha Pereira (Org.). Belo Horizonte: IBDFAM, pp. 27-98, 2015, p. 68.

HOLSTI, KaleviJ. (1991). Peace and War: Armed Conflicts and International Order, 1648-1989 Cambridge, Cambridge University Press.

KEEGAN, John. Uma História da guerra. São Paulo: Companhia das Letras, 1995. 
KOSSOY, B. História e Fotografia. 2. ed. São Paulo, Ateliê Editorial, 1989.

Realidades e Ficções na Trama Fotográfica. São Paulo, Ateliê Editorial, 1999.

LANES, Liton; SOBRINHO, Pilau. Direito à saúde: uma perspectiva constitucionalista. Passo Fundo: Ed. UPF, 2003.

LENZA, Pedro. Direito constitucional esquematizado. 12. ed. São Paulo: Saraiva, 2008

Manual de Emprego do Direito Internacional dos Conflitos Armados (DICA) nas Forças Armadas. MD34-M-03 - Ministério da Defesa - 1ª Edição/2011.

MÜLLER, Tânia Mara Pedroso. As aparências enganam? Fotografia e pesquisa. Petrópolis, RJ: De PetrusetAlii ; Rio de Janeiro: FAPERJ, 2011. 279 p.

NASCENTES, A. Dicionário etimológico da Língua Portuguesa. Rio de Janeiro, 1955.

PIOVESAN, Flávia. Direitos humanos e o direito constitucional internacional. São Paulo: Max Limonad, 2002.

PRADO, Magaly (org.); BUITONI, Dulcilia Schroeder. Fotografia e jornalismo. Coleção Introdução ao Jornalismo - v. 6. São Paulo: Saraiva, 2011. 208p.

PUCCINELLI, André Júnior. Curso de direito constitucional. São Paulo: Saraiva 2012.

SARLET, Ingo Wolfgang. A eficácia dos direitos fundamentais. 6. ed. rev. atual. Porto Alegre: Livraria do Advogado, 2006.

SINGER, David. (1979). The Correlates ofWar. New York, The Free Press.

SOUSA, Jorge Pedro. Fotojornalismo: introdução à história, às técnicas e à linguagem da fotografia na imprensa. Florianópolis: Letras Contemporâneas, 2004.

SOUZA, Esdras Dantas. Direitos e garantias individuais. Disponível em:Acesso em: 07 fev 2018.

SOUZA, Fernanda Oliveira. A intervenção judicial na garantia da efetivação do direito à saúde: possibilidades e limites no caso dos medicamentos. Disponível em: . Acesso em: 06 fev. 2018

TZU, Sun. A arte da guerra.São Paulo: Martins Fontes, 2002.

WARRY, John Gibson, e John Warry.Warfare in the Classical World: An Illustrated Encyclopedia of Weapons, Warriors and Warfare in the Ancient Civilisations of Greece and Rome.Universidade de Oklahoma Press: 1999. 